\title{
Age-related reduction of cerebral ischemic preconditioning: myth or reality?
}

This article was published in the following Dove Press journal:

Clinical Interventions in Aging

9 August 2013

Number of times this article has been viewed

\author{
David Della-Morte ${ }^{1,2}$ \\ Francesco Cacciatore ${ }^{3}$ \\ Elisa Salsano ${ }^{4}$ \\ Gilda Pirozzi ${ }^{4}$ \\ Maria Teresa Del Genio ${ }^{4}$ \\ lole D'Antonio ${ }^{4}$ \\ Gaetano Gargiulo 5 \\ Raffaele Palmirotta ${ }^{2}$ \\ Fiorella Guadagni \\ Tatjana Rundek' \\ Pasquale Abete ${ }^{4}$ \\ 'Department of Neurology, Miller \\ School of Medicine, University of \\ Miami, Miami, FL, USA; ${ }^{2}$ Department \\ of Advanced Biotechnologies and \\ Bioimaging, IRCCS San Raffaele, \\ Rome, Italy; ${ }^{3}$ Istituto Scientifico di \\ Campoli/Telese, Fondazione Salvatore \\ Maugeri, IRCCS, Benevento, Italy; \\ ${ }^{4}$ Dipartimento di Scienze Mediche \\ Traslazionali, Università di Napoli \\ "Federico II," Naples, Italy; ${ }^{5}$ AON, SS \\ Antonio e Biagio e Cesare Arrigo, \\ Struttura Complessa di Geriatria, \\ Alessandria, Italy
}

Correspondence: Pasquale Abete Dipartimento di Scienze Mediche Traslazionali, Università degli Studi di Napoli "Federico II", Via S. Pansini, 5 - 80I3I Naples, Italy Tel +39817462270

Fax +39817462339

Email p.abete@unina.it

\begin{abstract}
Stroke is one of the leading causes of death in industrialized countries for people older than 65 years of age. The reasons are still unclear. A reduction of endogenous mechanisms against ischemic insults has been proposed to explain this phenomenon. The "cerebral" ischemic preconditioning mechanism is characterized by a brief episode of ischemia that renders the brain more resistant against subsequent longer ischemic events. This ischemic tolerance has been shown in numerous experimental models of cerebral ischemia. This protective mechanism seems to be reduced with aging both in experimental and clinical studies. Alterations of mediators released and/or intracellular pathways may be responsible for age-related ischemic preconditioning reduction. Agents able to mimic the "cerebral" preconditioning effect may represent a new powerful tool for the treatment of acute ischemic stroke in the elderly. In this article, animal and human cerebral ischemic preconditioning, its age-related difference, and its potential therapeutical applications are discussed.
\end{abstract}

Keywords: ischemic preconditioning, stroke, transient cerebral ischemic attack, mortality, elderly

\section{Introduction}

Stroke and myocardial infarction account for more than $85 \%$ of death in patients older than 65 years. ${ }^{1,2}$ Accordingly, the incidence of acute stroke and myocardial infarction increases exponentially with age. ${ }^{3}$ The reasons for the high mortality for stroke and myocardial infarction in elderly patients are not clear although several factors seem to contribute to this phenomenon - risk factors such as hypertension, hyperlipidemia, and diabetes, age-related prothrombotic changes in the hemostatic system, a less aggressive therapy including thrombolytic therapy, and the presence of comorbidities. ${ }^{4}$ So, why is mortality for stroke and coronary artery disease higher in the elderly? This might be due, at least in part, to the age-related reduction of an endogenous powerful protective mechanism against ischemia. Aging can be defined as a progressive functional decline of an intrinsic, inevitable, and irreversible agerelated process of loss of viability and increase in vulnerability. ${ }^{5}$ Thus, one possibility is that the efficacy of endogenous protective mechanisms against ischemic disease might decrease with aging. ${ }^{6}$

\section{Ischemic preconditioning}

Ischemic preconditioning (IPC) is defined as brief episodes of ischemia followed by a long period of ischemia, representing the most powerful endogenous mechanism against the injurious effects of ischemia. ${ }^{7}$ Several studies in animals and humans have 
clearly demonstrated the capacity of IPC to protect organs against ischemic injury, including the brain. ${ }^{8,9}$ Moreover, IPC is classified as "early" when the protective effect occurs immediately during the first 1-3 hours after the ischemic episode ("first window"), and as "delayed" when the protective effect arises 24-72 hours after the ischemic episode ("second window"). ${ }^{10,11}$ Other forms of preconditioning have been recently discovered: "remote preconditioning" (in which ischemia in one region of an organ causes protection in a remote region of the same or of a different organ) $)^{12}$ and "postconditioning" in which brief episodes of artery occlusion and reperfusion at the onset of reperfusion after a sustained ischemic insult confer organ protection against ischemic-reperfusion injury. ${ }^{13}$ IPC has been widely investigated in clinical cardiology. Preinfarction angina, warm-up phenomenon, and transluminal coronary angioplasty are considered the clinical equivalents of IPC. ${ }^{10,11}$ It is important to note that the incidence of mortality and cardiogenic shock is reduced in patients with preinfarction angina. ${ }^{14}$

\section{IPC mechanism}

IPC mechanism has been widely investigated in the heart. ${ }^{15-18}$ From activation of G-protein coupled receptors by adenosine, norepinephrine, bradykinin, and opioids, phosphoinositide-3-kinase/protein kinase B is activated with subsequent downstream activation of nitric oxide synthase and nitric oxide formation, and guanylate cyclase, protein kinase $\mathrm{G}$, and protein kinase $\mathrm{C}$ (PKC) activation in acute ischemia. All these events lead to the opening of the mitochondrial adenosine triphosphate-dependent potassium channels through $\varepsilon$ PKC. The opening of mitochondrial adenosine triphosphate-dependent potassium channels results in an influx of potassium that causes swelling of the mitochondria, which is thought to lead to the production of reactive oxygen species. Reactive oxygen species formation results in p38 mitogen-activated kinase and $\mathrm{PKC}$ activation and subsequent "priming" of mitochondrial permeability transition pores. During early reperfusion after the preconditioning stimulus, activation of G-protein coupled receptors or of growth factor receptors results in activation of the reperfusion injury salvage kinase program. The reperfusion injury salvage kinase program involves the parallel activation of the phosphoinositide-3-kinase/protein kinase B and the extracellular regulated kinase system with downstream $\mathrm{p} 70$ ribosomal protein S6 kinase and glycogen synthase kinase $3 \beta$ activation leading to the inhibition of mitochondrial permeability transition pore opening with an increased survival of myocardial cells. ${ }^{15-18}$
IPC has also been found in the brain as demonstrated by mammalian in vivo and in vitro studies. ${ }^{19} \mathrm{~A}$ first demonstration of cerebral IPC has been found by inducing a sublethal ischemic stress, which protects against subsequent lethal ischemic injury in the hippocampal CA1 of transient global models of gerbils. ${ }^{20}$ Cerebral IPC was also confirmed in different experimental models, ie, transient focal or global ischemia rat model, ${ }^{21-23}$ focal ischemia model, ${ }^{24}$ blood-brain barrier models, ${ }^{25}$ in cultured neurons, ${ }^{26,27}$ in brain endothelial cells, ${ }^{28}$ and in oxygen-glucose-deprived rat hippocampal slices. ${ }^{29}$ Cerebral IPC was also demonstrated in a study of 12 adult patients with aneurismal subarachnoid hemorrhage by 2-minute proximal temporary artery occlusion followed by 30 minutes of reperfusion..$^{30}$ In this study, a multi-parameter catheter inserted in the artery demonstrated an improvement of oxygen tension, carbon dioxide, tension, and $\mathrm{pH}$ in tissue at risk of ischemia during temporary artery occlusion. Many stimuli, stressors, and chemicals may be considered "cerebral" preconditioning triggers. Hyperthermia, hypothermia, hypoxia, oxygen species, inflammatory cytokines, spreading depression, mitochondrial inhibition, resveratrol, volatile anesthetics, adenosine triphosphate-sensitive potassium channel openers, antibiotics, myelin basic proteins, and E-selectin induce resistance to ischemic injury in the brain. ${ }^{7,8}$ Moreover, IPC leads to a release of adenosine and glutamate into the extracellular space. In particular, glutamate, which is a physiological excitatory neurotransmitter, binds to ionotropic glutamate receptors such as N-methyl$\mathrm{D}$-aspartate receptor and $\alpha$-amino-3-hydroxy-5-methyl-4isoxazolepropionic acid. ${ }^{31}$ Excessive activation of glutamate receptors, particularly the N-methyl-D-aspartate receptor, causes a massive calcium influx that in turn activates several cell injury processes involving protease and lipase. These pathways, which are a part of the so-called glutamatecalcium theory, are believed to be central to the mechanism of cerebral ischemic tolerance and reperfusion injury salvage kinase activation (Figure 1).

\section{Transient ischemic attacks and cerebral IPC}

Several clinical reports support the existence of cerebral IPC in the human brain. The more typical clinical equivalent of cerebral IPC is Transient ischemic attack (TIA), which determines better outcomes in patients with ischemic stroke than those without TIA. ${ }^{32-36}$ On the other hand, vascular comorbidities highly prevalent in the elderly such as atrial fibrillation, valvular heart disease, coronary artery disease, and chronic heart failure are significant risk factors for TIA 


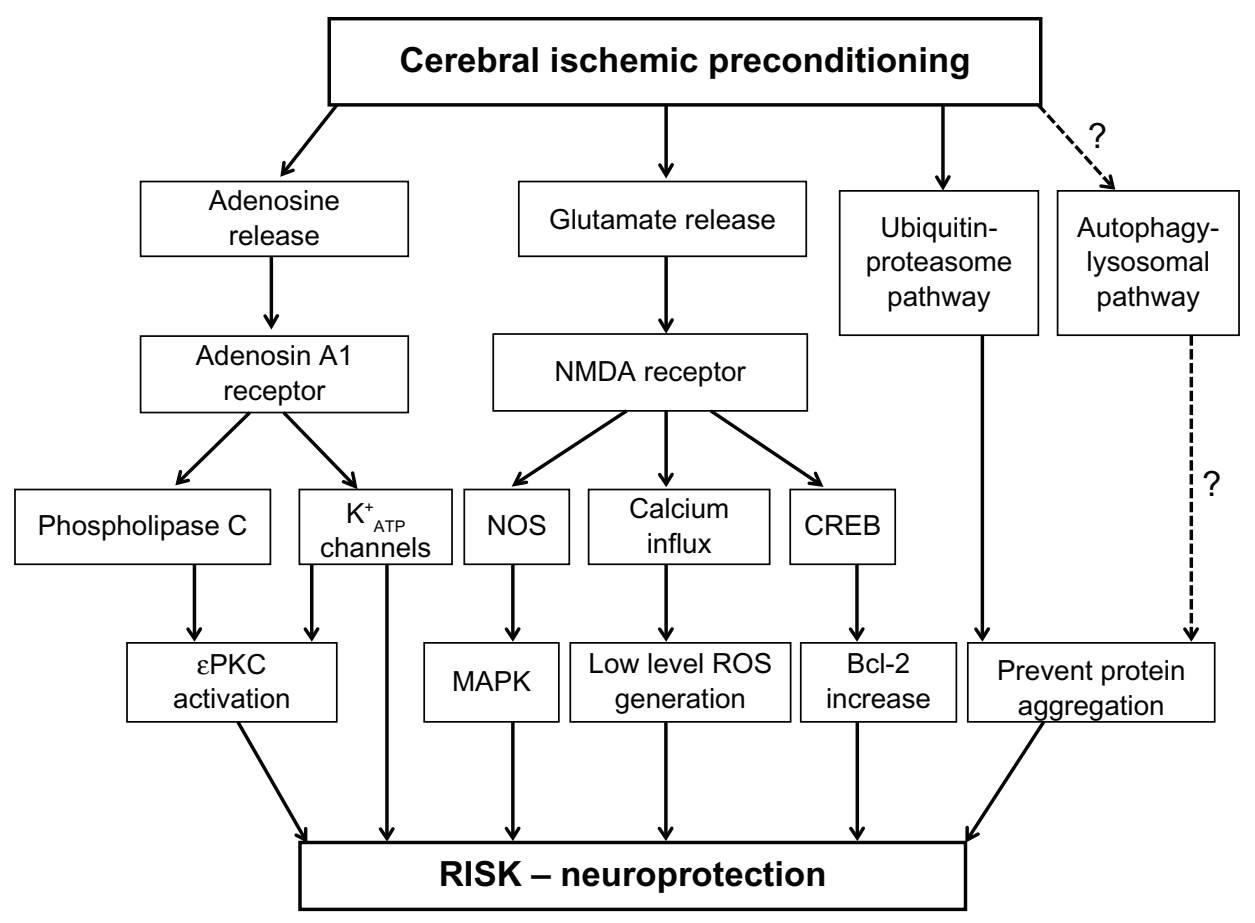

Figure I Signaling pathways involved in cerebral ischemic preconditioning. Triggering pathways include activation of the NMDA and adenosine AI receptors which in turn are involved in activating some intracellular signaling pathways such as MAPKs, PKC, bcl-2, heat shock proteins, ubiquitin-proteasome pathway, and autophagic-lysosomal pathway. These pathways probably involve activation of the RISK program.

Note: Adapted by permission from Macmillan Publishers Ltd. Liu XQ, Sheng R, Qin ZH. The neuroprotective mechanism of brain ischemic preconditioning. Acta Pharmacol Sin. (2009.

Abbreviations: ATP, adenosine triphosphate; bcl-2, b-cell lymphoma 2; CREB, cyclic adenosine monophosphate responsive element binding protein; MAPK, mitogenactivated protein kinase; NMDA receptor, N-methyl-D-aspartate receptor; NOS, nitric oxide synthase; PKC, protein kinase C; RISK, reperfusion injury salvage kinase; ROS, reactive oxygen species.

development. ${ }^{37}$ Thus, whether TIA preserves its protective effect represents a critical point in the prognosis of ischemic stroke in the elderly.

In a retrospective case-control study in 148 adult stroke patients with and without antecedent TIA, favorable clinical outcomes were significantly associated with the presence of prior TIA. ${ }^{32}$ Among 2,490 stroke patients younger than 65 years, 293 patients who had had ipsilateral TIA a few days before cerebral ischemic injury had favorable neurologic outcomes compared to patients without prior TIA. ${ }^{33}$ Prior TIA was associated with favorable outcomes in nonlacunar stroke in another study of 1,753 patients younger than 65 years of age. ${ }^{36}$ In addition, improved National Institutes of Health Stroke Scale score was demonstrated in adult patients who had a TIA 1-7 days before ischemic stroke. ${ }^{38}$ Finally, magnetic resonance images of patients with ischemic cerebral damage with and without TIA before stroke demonstrated that the extension of the lesion was clearly smaller in the patients with TIA prior to stroke. ${ }^{35}$ In contrast, in a cohort of 180 patients with TIA and subsequent ischemic stroke within 90 days of TIA, there was no association between duration of TIA - used as a surrogate for degree of ischemia - and likelihood of disability from a subsequent stroke. Furthermore, there was no difference in rates of disability among patients with strokes occurring within 1 day, 1 to $<7$ days, and 7-90 days after TIA. ${ }^{39}$

\section{Age-related reduction of IPC}

Experimental and clinical studies have demonstrated an age-related reduction of IPC-mediated protection in the aged heart. ${ }^{4}$ Age-related reduction of IPC was first demonstrated in the isolated and perfused rat heart from 24-month-old rats subjected to an IPC with a short period of ischemia ( 2 minutes) followed by 10 minutes of reperfusion (Figure 1A). ${ }^{4}$ Preinfarction angina exerted a beneficial effect on in-hospital outcomes in adult patients younger than 65 years of age but not in those patients 65 years of age or older (Figure 1B). Thus, IPC seems to be lost in senescent patients. ${ }^{4}$ Interestingly, caloric restriction and physical activity are able to restore IPC in aged hearts in both animals and humans. ${ }^{40}$ Several mechanisms have been proposed to explain the age-related reduction of IPC-mediated protection in the heart. An age-related reduction of norepinephrine release in response to "cardiac" IPC stimulus is one of the most accredited hypotheses. ${ }^{4}$ Moreover, several studies 
demonstrated an age-related impairment of IPC trigger and transduction mechanisms, eg, adenosine, PKC, and mitochondria metabolism. ${ }^{4}$

\section{Age-related reduction of cerebral IPC}

The protective effect of IPC in the brain has been well established in several animal studies. ${ }^{41}$ However, whether IPC is present in the aged brain is still unknown. ${ }^{42}$ In young animals, IPC protects CA1 hippocampal neurons against global ischemia. ${ }^{20}$ In a population of aged (18- to 20-month-old) gerbils, 10 days after ischemia there was over $80 \%$ protection of CA1 neurons in ischemic preconditioned animals compared with $6 \%$ in ischemic gerbils. CA1 cell survival declined to approximately $75 \%$ of sham values at 60 days after ischemia. ${ }^{43}$ Thus, IPC seems to provide a substantial neuroprotection in aged gerbils. However, the study did not compare young and aged gerbils. In a study where aged rats (4- and 24-months) were subjected to IPC (3-minute ischemia) followed by 10-minute ischemia, the assessments of histology and the immunoreactivity of N-methyl-D-aspartic acid receptor 1 and caspase- 3 active peptide in the hippocampal $\mathrm{CA} 1$ region were performed 8 days after full ischemia. The study showed that the degree of cerebral protection against full ischemia was reduced in the aged and preconditioned rats compared with the young rats (Figure $2 \mathrm{~A}$ and B) ${ }^{44}$

Similar to "cardiac" IPC, the clinical equivalent of "cerebral" IPC is TIA, a brief ischemic event occurring before a prolonged ischemic period in the same vascular territory leading to ischemic stroke. ${ }^{41,45,46}$ Studies conducted in patients with stroke younger than 65 years reported agefavorable clinical outcomes associated with prior TIA..$^{32-36,39}$ At present, data on "cerebral" IPC in elderly patients with stroke are limited. In a study of 203 patients aged 65 years or older with diagnosis of acute ischemic stroke, no significant differences in the admission or discharge National Institutes of Health Stroke Status and modified Rankin scores were observed between patients who had TIA ( $\mathrm{n}=42,21 \%)$ within 72 hours of stroke onset and those without TIA $(n=161$, $79 \%$ ) (Figure $3 \mathrm{~A}$ and B). ${ }^{47}$

Reduction of "cerebral" IPC protection in the aged brain may be due to the composite mechanisms that characterize the aged brain, ie, loss in number of neurons, impairment in the mitochondria function with an increase in reactive oxygen species production, alteration in gene expression and metabolic regulation, and alteration in intracellular calcium homeostasis. All these modifications make the organ more susceptible to stress such as ischemia. ${ }^{48}$ In particular, a gene
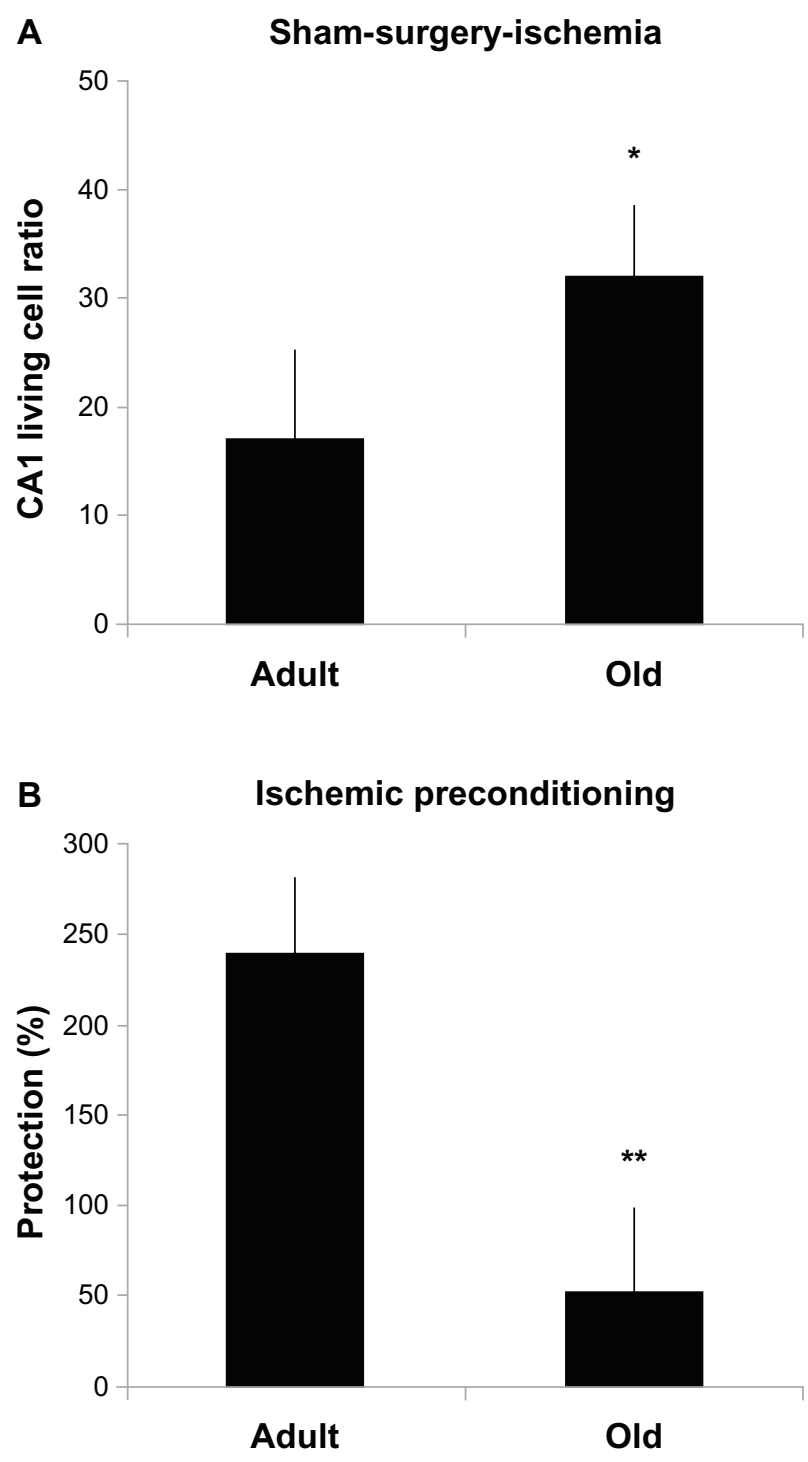

Figure 2 CAI "living cell ratio" was greater in the aged sham-surgery-ischemia group than in the young group $(32 \% \pm 6 \%$ versus $17 \% \pm 5 \%, * P<0.05)$ (A), whereas the degree of protection against full ischemia afforded by cerebral ischemic preconditioning was reduced in the aged compared with the young $(53 \% \pm 17 \%$ versus $241 \% \pm 25 \%$, $* * P<0.000 I$ ) (B).

expression profile following middle cerebral anterior occlusion shows reduced transcriptional activity, proapoptotic genes, and downregulation of axonogenesis and neurogenesis in the periinfarct area, which is more pronounced in aged versus young animals. ${ }^{49}$ These findings suggest that an aging brain is capable of upregulating gene expression, but the response is often blunted and temporally uncoordinated in response to cerebral ischemia. ${ }^{50}$

\section{Therapeutical attempts}

It is now established that IPC may be useful in cardiac surgery and cardiac transplantation as an adjunctive protective 
A

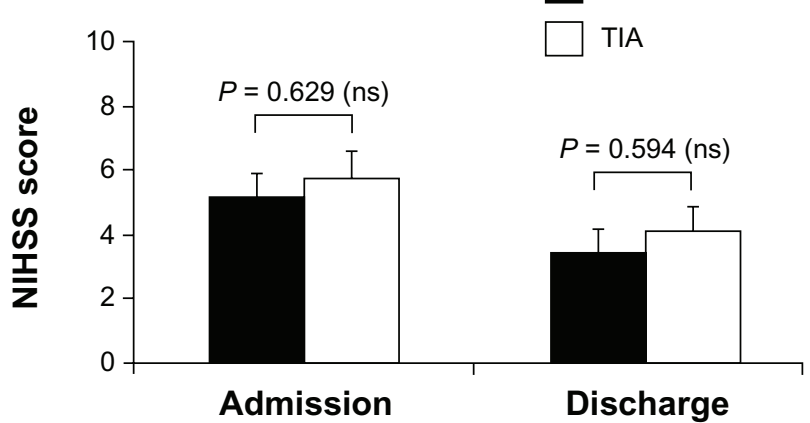

B

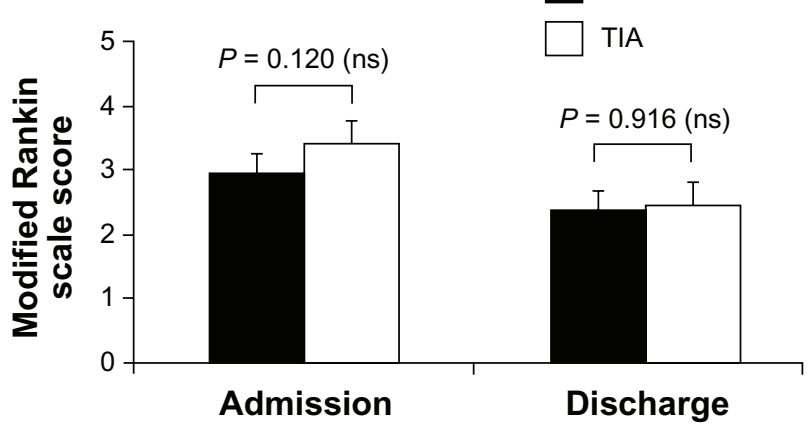

Figure 3 Neurologic status evaluated according to NIHSS (A) and disability assessed with modified Rankin scale (B) in elderly patients with or without TIA before stroke.

Note: Reprinted from Della-Morte D, Abete P, Gallucci F, et al. Transient ischemic attack before nonlacunar ischemic stroke in the elderly. J Stroke Cerebrovasc Dis. 2008; 17(5):257-262. ${ }^{47}$ @ 2008 with permission from Elsevier.

Abbreviations: NIHSS, National Institutes of Health Stroke Scale; ns, not significant; TIA, transient ischemic attack.

mechanism. ${ }^{11}$ The development and/or discovery of drugs or techniques able to mimic the IPC protective effect in the brain are still not ready for implementation in clinical practice. ${ }^{51}$ PKC isozyme-selective activators and inhibitors have been proposed as potential therapeutic compounds in both the heart and brain because of their capacity to mediate beneficial or injurious effects in response to ischemic insult. ${ }^{49}$ In particular, $\psi \varepsilon$-receptors for activated $\mathrm{C}$ kinase, an $\varepsilon \mathrm{PKC}$-selective peptide activator, injected intravenously 30 minutes before induction of global cerebral ischemia conferred neuroprotection in the CA1 region of the rat hippocampus. ${ }^{52}$ In contrast, it has been demonstrated that rats treated with $\delta$ PKC specific inhibitor $(\delta \mathrm{V} 1-1)$ prior to cerebral ischemia exhibited improved perfusion after 24 hours and less hippocampal CA1 neuronal death 7 days after arterial occlusion. ${ }^{53}$ These data suggest an opposite role of $\delta \mathrm{PKC}$ compared to $\varepsilon \mathrm{PKC}$ in the mechanism of IPC-mediated neuroprotection. Finally, resveratrol, a natural polyphenol found in grapes and wine, was able to mimic IPC inducing neuroprotection against ischemia in both in vitro and in vivo studies. ${ }^{54}$ In fact, resveratrol and IPC were able to increase sirtuin 1 activity and decrease uncoupling protein 2 at the mitochondrial level with the result of an increase in hippocampal mitochondrial oxygen consumption rates. The positive effects on restoring "cardiac" IPC in an aging heart by exercise training and caloric restriction has not been evaluated yet in the aging brain and awaits confirmation in a clinical trial. ${ }^{4}$

\section{Current studies and perspectives}

The reduction of cerebral IPC with age represents a strong rationale to induce IPC in elderly patients to therefore decrease stroke-related mortality. However, IPC application in clinical practice is still a future prospect. Based on the protective effect of intravenous administration of erythropoietin and its participation in ischemic tolerance, a multicenter randomized trial with acute ischemic stroke patients was performed to test the protective effects of recombinant erythropoietin administered within the 6-hour window after stroke onset. ${ }^{55}$ Unfortunately, the primary outcome measure failed to show a beneficial effect. Prior to carotid endarterectomy ${ }^{56}$ and after subarachnoid hemorrhage, ${ }^{57}$ the safety and feasibility of remote ischemic limb preconditioning has already been demonstrated in patients. Recently, the National Heart, Lung, and Blood Institute organized a preclinical consortium named the Consortium for Preclinical Assessment of Cardioprotective Therapies (CAESAR). This consortium will conduct studies by screening promising therapies and identifying those that are truly effective in relevant experimental models and thus most likely to be effective in patients. ${ }^{58,59}$ As underlined previously, IPC was first identified in the heart and successively in the brain. It is likely that some of the processes essential for the development of IPC are the same in both tissues.

\section{Conclusion}

Accumulating evidence clearly shows that preconditioning of the brain with a short period of ischemia activates specific pathways able to protect the brain from a prolonged ischemic insult and improves outcomes if the ischemic events occur. However, this powerful protective mechanism seems to be reduced in aging brains in both animal and human studies. The possible absence of preconditioning capacity in the brain may account, in part, for the higher mortality from stroke observed in elderly patients. Agents able to mimic the "cerebral" preconditioning effect may represent a new and powerful therapeutic option for the treatment of acute ischemic stroke in the elderly. Further studies are needed to establish the age-related reduction of "cerebral" IPC in the aging brain and translate these discoveries to clinical practice. 


\section{Acknowledgments}

Tatjana Rundek and David Della-Morte were supported by the NIH/NINDS K24 NS 062737 grant.

\section{Disclosure}

The authors report no conflicts of interest in this work.

\section{References}

1. DeFrances CJ, Hall MJ, Podgornik MN. Advance Data From Vital and Health Statistics No 359: 2003 National Hospital Discharge Survey. Hyattsville, MD: National Center for Health Statistics; 2005. Available from: http://www.cdc.gov/nchs/data/ad/ad359.pdf. Accessed July 7, 2013.

2. Truelsen T, Piechowski-Jozwiak B, Bonita R, Mathers C, Bogousslavsky J, Boysen G. Stroke incidence and prevalence in Europe: a review of available data. Eur J Neurol. 2006;13(6):581-598.

3. Go AS, Mozaffarian D, Roger VL, et al; American Heart Association Statistics Committee and Stroke Statistics Subcommittee. Executive summary: heart disease and stroke statistics - 2013 update: a report from the American Heart Association. Circulation. 2013;127(1):143-152.

4. Abete $\mathrm{P}$, Cacciatore $\mathrm{F}$, Testa $\mathrm{G}$, et al. Ischemic preconditioning in the aging heart: from bench to bedside. Ageing Res Rev. 2010;9(2):153-162.

5. Comfort A. Biological theories of aging. Hum Dev. 1970;13(2): 127-139.

6. Jahangir A, Sagar S, Terzic A. Aging and cardioprotection. J Appl Physiol. 2007;103(6):2120-2128.

7. Murry CE, Jennings RB, Reimer KA. Preconditioning with ischemia: a delay of lethal cell injury in ischemic myocardium. Circulation. 1986;74(5):1124-1136.

8. Dirnagl U, Simon RP, Hallenbeck JM. Ischemic tolerance and endogenous neuroprotection. Trends Neurosci. 2003;26(5):248-254.

9. Liu XQ, Sheng R, Qin ZH. The neuroprotective mechanism of brain ischemic preconditioning. Acta Pharmacol Sin. 2009;30(8):1071-1080.

10. Kloner RA, Bolli R, Marban E, Reinlib L, Braunwald E. Medical and cellular implications of stunning, hibernation, and preconditioning: an NHLBI workshop. Circulation. 1998;97(18):1848-1867.

11. Yellon DM, Downey JM. Preconditioning the myocardium: from cellular physiology to clinical cardiology. Physiol Rev. 2003;83(4):1113-1151.

12. Przyklenk K, Whittaker P. Remote ischemic preconditioning: current knowledge, unresolved questions, and future priorities. J Cardiovasc Pharmacol Ther. 2011;16(3-4):255-259.

13. Vinten-Johansen J, Shi W. Perconditioning and postconditioning: current knowledge, knowledge gaps, barriers to adoption, and future directions. J Cardiovasc Pharmacol Ther. 2011;16(3-4):260-266.

14. Kloner RA, Shook T, Przyklenk K, et al. Previous angina alters inhospital outcome in TIMI 4: a clinical correlate to preconditioning? Circulation. 1995;91(1):37-45.

15. Hausenloy DJ, Yellon DM. Survival kinases in ischemic preconditioning and postconditioning. Cardiovasc Res. 2006;70(2):240-253.

16. Halestrap AP, Clarke SJ, Khaliulin I. The role of mitochondria in protection of the heart by preconditioning. Biochim Biophys Acta. 2007;1767(8):1007-1031.

17. Heusch G, Boengler K, Schulz R. Cardioprotection: nitric oxide, protein kinases, and mitochondria. Circulation. 2008;118(19):1915-1919.

18. Hausenloy DJ, Ong SB, Yellon DM. The mitochondrial permeability transition pore as a target for preconditioning and postconditioning. Basic Res Cardiol. 2009;104(2):189-202.

19. Perez-Pinzon MA. Neuroprotective effects of ischemic preconditioning in brain mitochondria following cerebral ischemia. J Bioenerg Biomembr. 2004;36(4):323-327.

20. Kitagawa K, Matsumoto M, Tagaya M, et al. "Ischemic tolerance" phenomenon found in the brain. Brain Res. 1990;528(1):21-24.
21. Stagliano NE, Perez-Pinzon MA, Moskowitz MA, Huang PL. Focal ischemic preconditioning induces rapid tolerance to middle cerebral artery occlusion in mice. J Cereb Blood Flow Metab. 1999;19(7):757-761.

22. Nishi S, Taki W, Uemura Y, et al. Ischemic tolerance due to the induction of HSP70 in a rat ischemic recirculation model. Brain Res. 1993;615(2):281-288.

23. Dave KR, Saul I, Busto R, Ginsberg MD, Sick TJ, Perez-Pinzon MA. Ischemic preconditioning preserves mitochondrial function after global cerebral ischemia in rat hippocampus. J Cereb Blood Flow Metab. 2001;21(12):1401-1410.

24. Chen Y, Ruetzler C, Pandipati S, et al. Mucosal tolerance to E-selectin provides cell-mediated protection against ischemic brain injury. Proc Natl Acad Sci U S A. 2003;100(25):15107-15112.

25. Gesuete R, Orsini F, Zanier ER, et al. Glial cells drive preconditioninginduced blood-brain barrier protection. Stroke. 2011;42(5):1445-1453.

26. Grabb MC, Choi DW. Ischemic tolerance in murine cortical cell culture: critical role for NMDA receptors. J Neurosci. 1999;19(5): 1657-1662.

27. Blondeau N, Widmann C, Lazdunski M, Heurteaux C. Activation of the nuclear factor- $\mathrm{\kappa B}$ is a key event in brain tolerance. $J$ Neurosci. 2001;21(13):4668-4677.

28. Andjelkovic AV, Stamatovic SM, Keep RF. The protective effects of preconditioning on cerebral endothelial cells in vitro. $J$ Cereb Blood Flow Metab. 2003;23(11):1348-1355.

29. Xu GP, Dave KR, Vivero R, Schmidt-Kastner R, Sick TJ, Perez-Pinzon MA. Improvement in neuronal survival after ischemic preconditioning in hippocampal slice cultures. Brain Res. 2002;952(2): 153-158.

30. Chan MT, Boet R, Ng SC, Poon WS, Gin T. Effect of ischemic preconditioning on brain tissue gases and $\mathrm{pH}$ during temporary cerebral artery occlusion. Acta Neurochir Suppl. 2005;95:93-96.

31. Bond A, Lodge D, Hicks CA, Ward MA, O'Neill MJ. NMDA receptor antagonism, but not AMPA receptor antagonism attenuates induced ischemic tolerance in the gerbil hippocampus. Eur J Pharmacol. 1999;380(2-3):91-99.

32. Weih M, Kallenberg K, Bergk A, et al. Attenuated stroke severity after prodromal TIA: a role for ischemic tolerance in the brain? Stroke. 1999;30(9):1851-1854.

33. Moncayo J, de Freitas GR, Bogousslavsky J, Altieri M, van Melle G. Do transient ischemic attacks have a neuroprotective effect? Neurology. 2000;54(11):2089-2094.

34. Castillo J, Moro MA, Blanco M, et al. The release of tumor necrosis factor- $\alpha$ is associated with ischemic tolerance in human stroke. Ann Neurol. 2003;54(6):811-819.

35. Wegener S, Gottschalk B, Jovanovic V, et al; MRI in Acute Stroke Study Group of the German Competence Network Stroke. Transient ischemic attacks before ischemic stroke: preconditioning the human brain? A multicenter magnetic resonance imaging study. Stroke. 2004;35(3):616-621.

36. Arboix A, Cabeza N, Garcia-Eroles L, et al. Relevance of transient ischemic attack to early neurological recovery after nonlacunar ischemic stroke. Cerebrovasc Dis. 2004;18(4):304-311.

37. Galizia G, Abete P, Mussi C, et al. Role of early symptoms in assessment of syncope in elderly people: results from the Italian group for the study of syncope in the elderly. J Am Geriatr Soc. 2009;57(1):18-23.

38. Schaller B. Ischemic preconditioning as induction of ischemic tolerance after transient ischemic attacks in human brain: its clinical relevance. Neurosci Lett. 2005;377(3):206-211.

39. Johnston SC. Ischemic preconditioning from transient ischemic attacks? Data from the Northern California TIA Study. Stroke. 2004;35(11 Suppl 1): 2680-2682.

40. Abete P, Ferrara N, Cacciatore F, et al. High level of physical activity preserves the cardioprotective effect of preinfarction angina in elderly patients. J Am Coll Cardiol. 2001;38(5):1357-1365.

41. Perez-Pinzon MA. Mechanisms of neuroprotection during ischemic preconditioning: lessons from anoxic tolerance. Comp Biochem Physiol A Mol Integr Physiol. 2007;147(2):291-299. 
42. Della-Morte D, Caso V, Guadagni F. A continuous debate about cerebral ischemic preconditioning in the elderly. J Neurol Neurophysiol. 2011;2:101e.

43. Dowden J, Corbett D. Ischemic preconditioning in 18- to 20-month-old gerbils: long-term survival with functional outcome measures. Stroke. 1999;30(6):1240-1246.

44. He Z, Crook JE, Meschia JF, Brott TJ, Dickson DW, McKinney M. Aging blunts ischemic preconditioning-induced neuroprotection following transient global ischemia in rats. Curr Neurovasc Res 2005;2(5):365-374.

45. Schaller B, Graf R. Cerebral ischemic preconditioning. An experimental phenomenon or a clinical important entity of stroke prevention? J Neurol. 2002;249(11):1503-1511.

46. Kitagawa K. Ischemic tolerance in the brain: endogenous adaptive machinery against ischemic stress. J Neurosci Res. 2012;90(5): 1043-1054.

47. Della-Morte D, Abete P, Gallucci F, et al. Transient ischemic attack before nonlacunar ischemic stroke in the elderly. J Stroke Cerebrovasc Dis. 2008;17(5):257-262.

48. Shankar SK. Biology of aging brain. Indian J Pathol Microbiol.2010;53(4): 595-604.

49. Budas GR, Churchill EN, Mochly-Rosen D. Cardioprotective mechanisms of PKC isozyme-selective activators and inhibitors in the treatment of ischemia-reperfusion injury. Pharmacol Res. 2007;55(6): 523-536.

50. Della-Morte D, Guadagni F, Palmirotta R, et al. Genetics of ischemic stroke, stroke-related risk factors, stroke precursors and treatments. Pharmacogenomics. 2012;13(5):595-613.

51. Koch S, Sacco RL, Perez-Pinzon MA. Preconditioning the brain: moving on to the next frontier of neurotherapeutics. Stroke. 2012;43(6): 1455-1457.
52. Della-Morte D, Raval AP, Dave KR, Lin HW, Perez-Pinzon MA Post-ischemic activation of protein kinase $\mathrm{C} \varepsilon$ protects the hippocampus from cerebral ischemic injury via alterations in cerebral blood flow. Neurosci Lett. 2012;487(2):158-162.

53. Lin HW, Della-Morte D, Thompson JW, et al. Differential effects of $\delta$ and $\varepsilon$ protein kinase $\mathrm{C}$ in modulation of postischemic cerebral blood flow. Adv Exp Med Biol. 2012;737:63-69.

54. Della-Morte D, Dave KR, DeFazio RA, Bao YC, Raval AP, Perez-Pinzon MA. Resveratrol pretreatment protects rat brain from cerebral ischemic damage via a sirtuin 1-uncoupling protein 2 pathway. Neuroscience. 2009;159(3):993-1002.

55. Ehrenreich H, Weissenborn K, Prange H, et al; EPO Stroke Trial Group. Recombinant human erythropoietin in the treatment of acute ischemic stroke. Stroke. 2009;40(12):e647-e656.

56. Walsh SR, Nouraei SA, Tang TY, Sadat U, Carpenter RH, Gaunt ME. Remote ischemic preconditioning for cerebral and cardiac protection during carotid endarterectomy: results from a pilot randomized clinical trial. Vasc Endovascular Surg. 2010;44(6):434-439.

57. Koch S, Katsnelson M, Dong C, Perez-Pinzon M. Remote ischemic limb preconditioning after subarachnoid hemorrhage: a Phase Ib study of safety and feasibility. Stroke. 2011;42(5):1387-1391.

58. Lefer DJ, Bolli R. Development of an NIH Consortium for Preclinical Assessment of Cardioprotective Therapies (CAESAR): a paradigm shift in studies of infarct size limitation. J Cardiovasc Pharmacol Ther. 2011;16(3-4):332-339.

59. Abete P, Testa G, Della-Morte D, et al. Treatment for chronic heart failure in the elderly: current practice and problems. Heart Fail Rev. 2013;18(4):529-51.
Clinical Interventions in Aging

\section{Publish your work in this journal}

Clinical Interventions in Aging is an international, peer-reviewed journal focusing on evidence-based reports on the value or lack thereof of treatments intended to prevent or delay the onset of maladaptive correlates of aging in human beings. This journal is indexed on PubMed Central, MedLine, the American Chemical Society's 'Chemical Abstracts Ser-

\section{Dovepress}

vice' (CAS), Scopus and the Elsevier Bibliographic databases. The manuscript management system is completely online and includes a very quick and fair peer-review system, which is all easy to use. Visit http://www.dovepress.com/testimonials.php to read real quotes from published authors. 